\title{
A NEW FLIGHTLESS DOLICHOCTIS (COLEOPTERA: CARABIDAE) FROM SUMBAWA*
}

\author{
By P. J. Darlington, Jr. \\ Museum of Comparative Zoology
}

The genus Dolichoctis, of the tribe Lebiini, includes a large number of small Carabidae of the Oriental-Australian area. They are characterized by size (length often $c .5 \mathrm{~mm}$ or less), by details of the mouthparts (which need not be given here - see Darlington I 968 , I24), and almost always by presence of 2 minute punctures without setae on the posterior half of the third interval of each elytron. Most are arboreal, occurring often in under-story foliage of rain forest, although a few species probably occur in leaf litter on the ground. All previously known Dolichoctis are fully winged, so far as I know. The finding of a species in which wing atrophy has occurred is therefore of special interest. Atrophy of wings is in fact rare among all the Lebiini of the Indo-Australian islands: of I6o members of the tribe found on New Guinea, only one has reduced wings (Nototarus papua Darlington 1968, I86). Of course wing atrophy is very common among some other Carabidae in some other parts of the world (Darlington 1936; 1943).

\section{Dolichoctis pedestris n. sp.}

(Fig. I )

Description. With characters of genus; form as in Fig. I; dark brown, reflexed elytral margins, legs, mouthparts, and antennal bases brownish-yellow, antennae darker from parts of 3rd segments; reticulate microsculpture heavy and isodiametric on front, distinct and somewhat transverse on pronotum, lighter and more transverse on elytra. Head 0.75 and 0.73 width prothorax; 2 strong presumably formerly seta-bearing punctures over each eye. Prothorax subcordate; width/length I.22 and I.27; base/apex 0.92 and I.O2; lateral margins moderate and moderately reflexed, without setae or seta-bearing punctures; disc weakly convex, with virtually entire impressed middle line, transverse impressions obsolete, baso-lateral impressions weak, surface across base irregular but not distinctly punctate. Elytra short, wide; width elytra/prothorax $\mathrm{I} .77$ and $\mathrm{r} .86$ (proportions approximate, because elytra slightly spread in all specimens); apices obliquely truncate with sutural angles narrowly

*Manuscript received by the editor January 28, 1970 


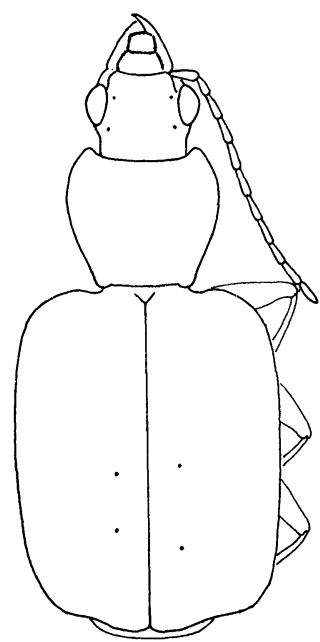

Fig. 1. Dolichoctis pedestris n. sp., Holotype.

rounded; striae entire, impressed, not distinctly punctate; intervals slightly convex, 3rd with 2 small impressed points without setae behind middle. Lower surface virtually impunctate; abdomen not pubescent. Inner wings reduced to vestiges less than $1 / 2$ length of elytra. Legs slender; 4 th hind-tarsal segments long, subtruncate; 5 th segments without obvious accessory setae (latter probably small, weak, and mostly broken off); claws each with $c .4$ teeth. Secondary sexual characters: $\sigma^{\pi}$ front tarsi apparently not dilated and apparently without squamules (condition of specimens prevents certain determination of presence or absence of squamules); I seta each side last ventral segment in both sexes. Measurements: length c. $4.8-5.5$; width c. $2.3-2.7 \mathrm{~mm}$.

Types. Holotype $\sigma^{x}$ (sex determined by dissection) and 3 paratypes ( $\mathrm{I}$ in M. C. Z., Type No. 31,675) all from "B. Aroe Hassa," Sambawa (Sumbawa), 2000-5000 ft. (about 600-I $500 \mathrm{~m}$ ), Sept., Oct. (Doherty).

Notes. The atrophy of the wings is unique in this genus, so far as I know, and loss of the lateral prothoracic setae is exceptional also. Otherwise, in Jedlicka's (1963, 356) key to East Asiatic (=Oriental) Dolichoctis, the present new species runs to D. gilvipes Dejean of the Philippines, but terrestris is larger, with eyes less prominent and prothorax narrower and with sides much less sinuate 
posteriorly; and in my (I968, I26) key to New Guinean Dolichoctis, it runs to couplet 2 but has the prothorax much narrower than striata Schmidt-Goebel and the elytra much wider and without the maculation of microdera Andrewes.

Atrophy of wings and loss of prothoracic setae suggest that this insect, although derived from a primarily arboreal, winged, mainly lowland stock, is adapted to a mountain habitat, perhaps to living in leaf litter on the ground in montane rain forest.

Darlington, P. J., JR.

\section{REFERENCES}

1936. Variation and atrophy of flying wings of some carabid beetles. Ann. Ent. Soc. America 29(1): 136-179.

1943. Carabidae of mountains and islands: data on the evolution of isolated faunas, and on atrophy of wings. Ecological Monographs 13(1): 37-61.

1968. The carabid beetles of New Guinea. Part III. Harpalinae (continued): Perigonini to Pseudomarphini. Bull. Mus. Comp. Zool. $137(1): 1-253$.

Jedlicka, Arnost.

1963. Monographie der Truncatipennen aus Ostasien. Ent. Abhandlungen $28(7): 269-579$. 

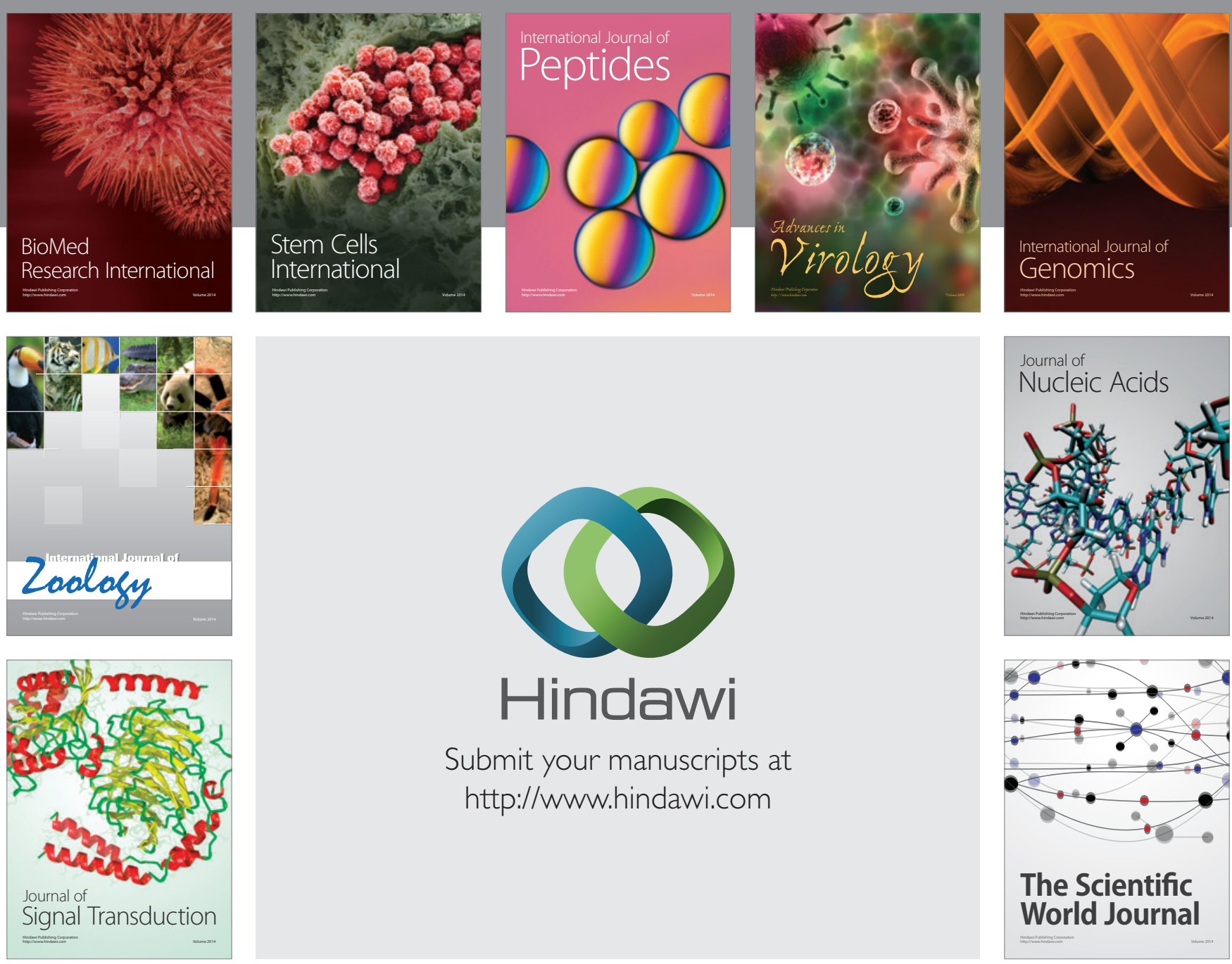

Submit your manuscripts at

http://www.hindawi.com
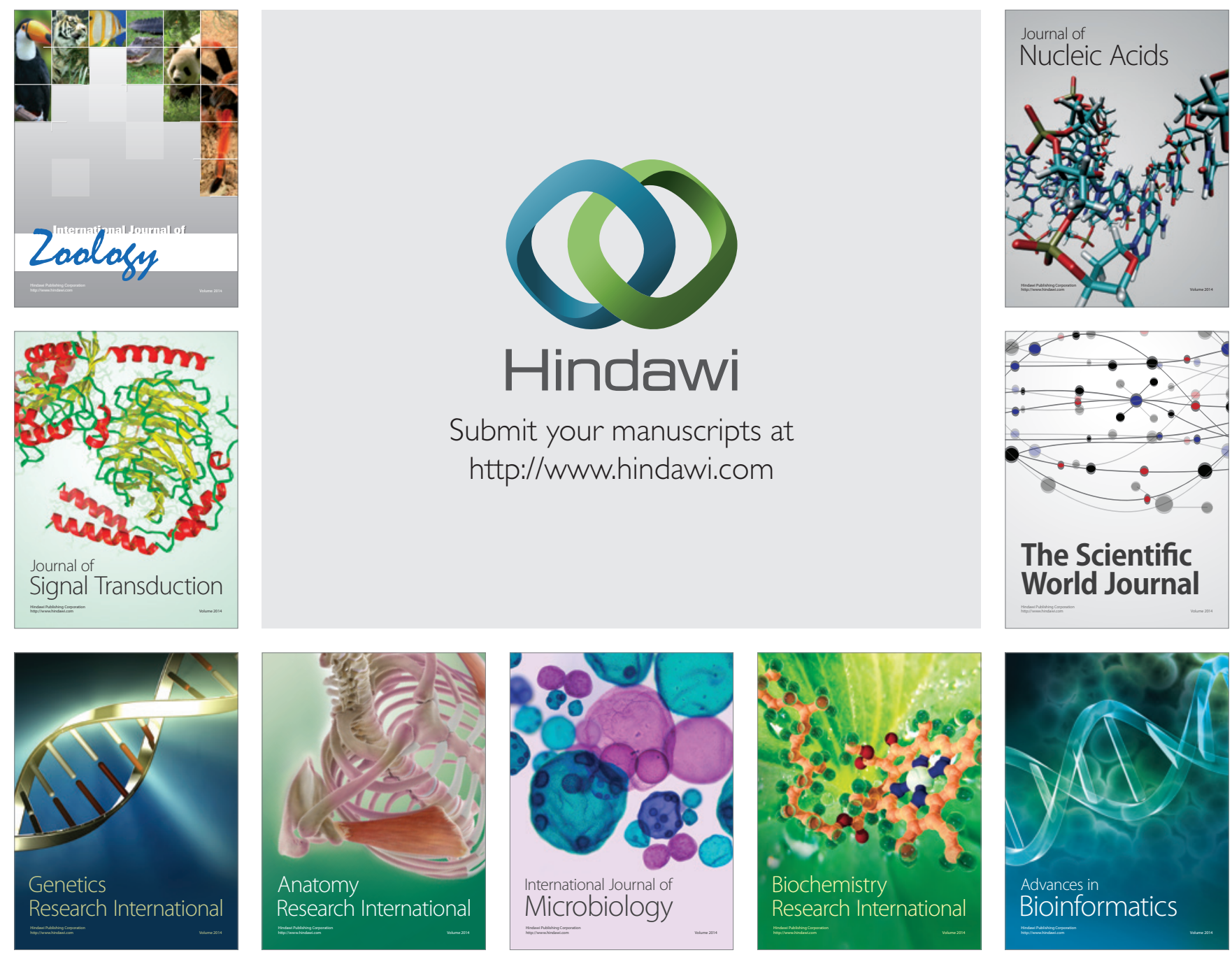

The Scientific World Journal
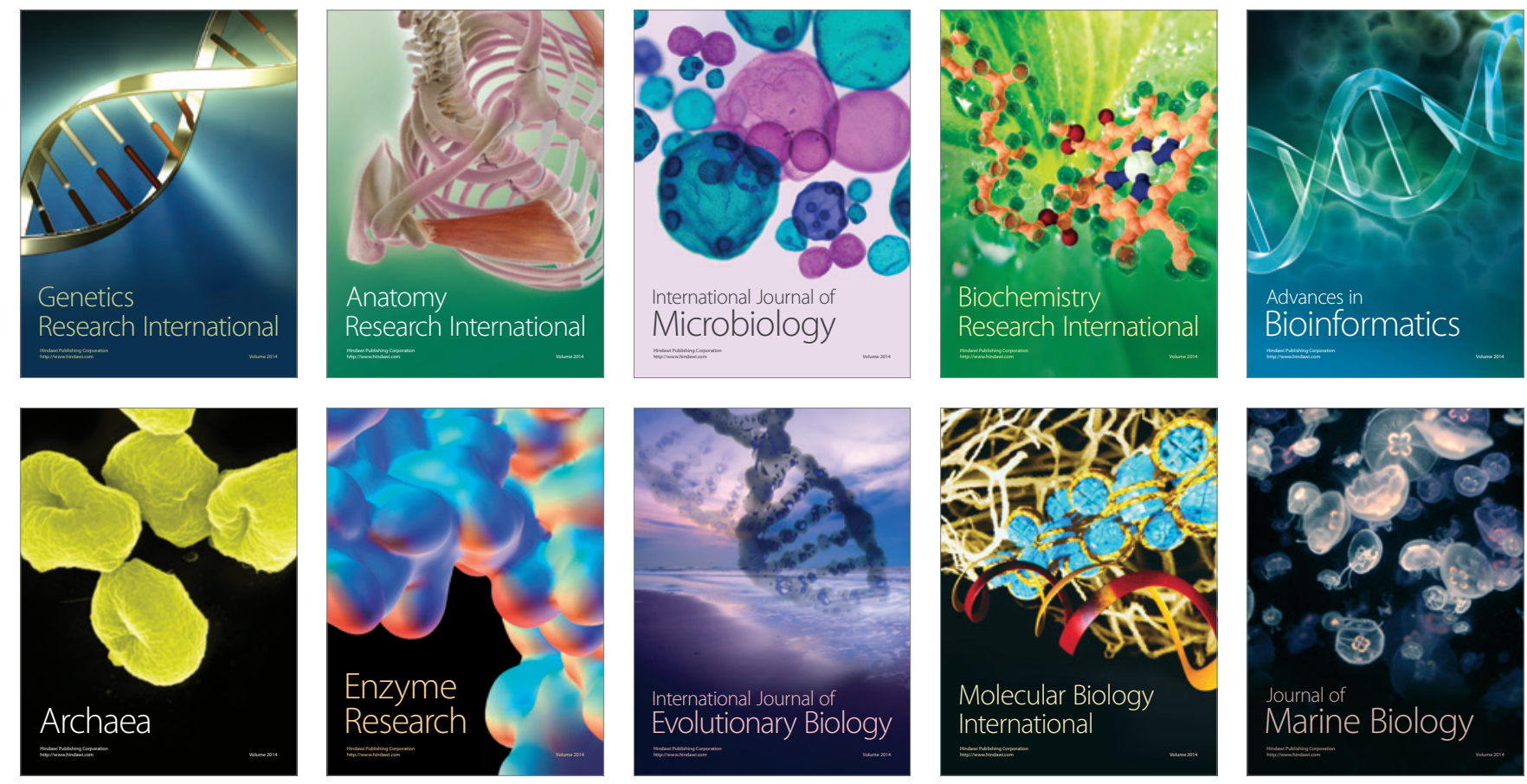